\title{
Study on Teaching Mode of "Double Qualified Teachers and Double Guidance" and Learning and Working Alternation
}

\author{
Limei Guo \\ Yibin Vocational and Technical College \\ Yibin, Sichuan, China 644003
}

\author{
Yang Mou \\ Yibin Vocational and Technical College \\ Yibin, Sichuan, China 644003
}

\author{
Ronghua Li \\ Yibin Vocational and Technical College \\ Yibin, Sichuan, China 644003
}

\begin{abstract}
In recent years, many higher vocational colleges in our country have carried out some reform attempts of practical course teaching for architectural decoration specialty. But whether the practice mode of "studio system integrating teaching, learning and doing" or the practice mode of "decoration engineering experience center", problems still exist in the systemic and integrity of systematic study of theory, practice teaching system and theoretical course system, as well as the cooperation mechanism between internal teachers and external teachers and enterprises. "Double qualified teachers and double guidance" is a new model of teaching reform for architectural decoration specialty in higher vocational colleges based on constructivism, enable students to study in the project in real working environment, transform students' practical process to learning process, to improve the talent cultivation quality of architectural decoration specialty, provide students with the social integration environment, and provide enterprises with early stage talent training, thus to achieve win-win purpose.
\end{abstract}

Keywords-architectural decoration; learning and working alternation; double qualified teachers and double guidance

\section{INTRODUCTION}

Higher vocational education has the double attribute of higher education and vocational education, taking the cultivation of high-end skilled talents of production, construction, service, first-line management as the main task. Cultivation of the key ability of students in higher vocational colleges is to cultivate the future practical technical personnel's personality beyond its occupational area and working field, so that they can adapt to the new changes from all sides, laying a foundation for sustainable development of talents, which is the direction of specialty construction and problem needed to be solved for teaching reform. Architectural decoration specialty in higher vocational colleges cultivates technology applied talents with comprehensive vocational ability of architectural decoration. Students need to accumulate a certain amount of practical experience throughout the whole

Fund Project: Research achievement of Teaching Mode Reform of "Learning and Working Alternation and Double Qualified Teachers" for Architectural Decoration Specialty supported by Sichuan Provincial Department of Education. knowledge system; architectural decoration companies expect the graduates have good professional ethics, teamwork, hard working and dedication spirit; and the graduates are expected to be good at many things and expert in one in terms of specialty, and have good post adaptation ability. But the current architectural decoration specialty of higher vocational colleges still has problems in actual promotion of practice teaching system.

\section{MAIN PROBLEMS EXIST IN TALENT CULTIVATION OF CURRENT ARCHITECTURAL DECORATION SPECIALTY}

\section{A. Enterprises Have No Long-Term Mechanism as Support and Lack of Participation, and There is Conflict between Company Activities and Teaching Activities}

The main role of industry and enterprise hasn't played fully in terms of practical teaching approach realization. For example, school plays the absolute dominant role in teaching plan formulation and teaching contents arrangement, rather than to be formulated by enterprise or related technology association, and certify the school-running of higher vocational education using such standards. At the same time, most of offcampus practice teaching bases are established and maintained relying on relationship without an effective long-term mechanism, and it is difficult to be stabilized. In addition, enterprises' pursuit of maximization of economic benefit conflicts with the higher vocational education' talent cultivation goal of "zero adapting period", resulting in a lot of enterprises are not keen on base construction, and are unwilling to accept students' practical training and practice. In cooperation with enterprise, schools haven't considered the enterprises' profitability and take no necessary measures to promote both parties establish a comprehensive, deep and close relations of cooperation, thus the "mutually beneficial and win-win" situation is unable to be formed. Therefore, in teaching practice, although schools have paid attention to play the enterprise's role, it hasn't been transited to "double main 
body", namely take both the school and enterprise as main body.

\section{B. Construction of Practice Teachers is Relatively Lagged behind, and Teachers' Practical Ability and Teaching Level is Uneven}

The practice teaching teachers are insufficient and lack of practical experience, with weak operation ability, low overall quality, and the practice teacher cultivation, evaluation and incentive mechanism is not imperfect. Moreover, most of the teachers work in school directly after they graduated from school, lack of practical experience, so they are often unable to correctly guide students to complete the training task, some even mislead students, lead to the practice teaching effect greatly reduced.

\section{Theory is Devoiced from Practice in Cognitive Process}

The decoration specialty of higher vocational colleges shall cultivate such applied and technical talents with solid theoretical foundation knowledge, strong operation ability and skills, and certain innovation ability, who are able to use the knowledge flexibly to analyze problems, and can adapt to the production, operation, management and first-line service. But the traditional classroom teaching still adopts the simple teaching method of theory teaching by teachers, which is easy to produce the undesirable tendency of emphasizing theoretical teaching and neglecting practical operation, and cannot meet the needs of enterprises for high vocational students' skill level. At the same time, the traditional classroom teaching is basically the mechanical teaching mode of "students listen to the teacher's lecture, copy the teacher's writing and recite what the teacher will test". This kind of teaching wastes time and energy with less knowledge output; emphasizing theory and neglecting practice will make no good teaching effect, and it is difficult to mobilize students' learning enthusiasm and initiative. In traditional teaching mode, the architectural practice teaching is mostly established on virtual project, students cannot consider from the overall design of art, technology and economy, just focus on the pursuit of artistic form, ignore the practical problems of technology and cost, results in a serious disconnect between artistic conception and practice. Students seem to be unable to adapt to specific work due to lack of the opportunities to use the knowledge and skills.

In order to further deepen the reform and construction of the connotation of architectural decoration specialty and to implement the deep integration of school and enterprise, we explore the talent cultivation mode of learning and working alternation with "double qualified teachers and double guidance" as emphasis to solve these problems.

\section{IMPLEMENTATION OF PRACTICE TEACHING MOdE OF “DOUble QuAlified TeACHERS AND DOUBle GuIDANCE" AND STUDENTS' INTEREST STIMULATION}

\section{A. Teaching Mode Design based on Constructivism Learning Theory and Environmental Learning Theory}

The thought of constructivism is originated from cognitive processing theory, as well as the ideas of Vygotsky, Piaget and
Bruner. Constructivism learning theory is a branch of cognitive learning theory. This theory held that learning is the process of acquiring knowledge. Knowledge is not obtained by teacher's teaching, but obtained through meaning construction by the learners in certain economic and social cultural background, with the help of others (including teachers and learning partners), using necessary learning materials. It advocates the learning style with students as the center under the guidance of teachers, which will not only highlight students' cognitive subject position in the learning process, but the teacher's role of guidance will not be ignored. It not only requires the students to transform into the main body of information processing and active builder of knowledge meaning from passive recipients of external stimulation and knowledge infusion subject; but also requires teachers to transform into the helper and facilitator for students to construct meaning actively from the initiator and indoctrinator of knowledge.

And the learning environment is an important basic concept of constructivism learning theory. The definition relating to education technology published by American Association of Education Communication and Technology (AECT) in 1994 is the education technology definition now widely recognized in China: Education technology is the theory and practice about design, development, utilization, management and evaluation of learning resources and learning process. The definition describes the research object of education technology as a series of theory and practice problems relating to "learning process" and "learning resources", which has changed the previous formulation of "teaching process", reflecting that the modern teaching concept has transformed to learning-centered from teachingcentered, and has transformed to developing students' learning ability from imparting knowledge. Learning process is the cognitive process of acquiring knowledge and skills by learners through interaction with information and the environment. Learning resources are the various information and environmental conditions to be used in the process of learning. New teaching theory requires students to transform into the active learners who can actively conduct the information processing from the passive recipients of external stimulus, and requires teachers to offer the information resources and learning environment to help and promote students' learning.

\section{B. Implementation of the Practice Teaching Mode of "Double Qualified Teachers and Double Guidance" and the Effect}

We set up the practice teaching mode of "double qualified teachers and double guidance" based on the constructivism learning theory, namely, arrange the time and place, people and learning content in the teaching plan, to build a peoplecentered environment learning mode, with the details as below.

Construct the tutor team for students in their learning period of working and learning alternation with professional teachers and enterprise teachers. The working and learning alternation is implemented for students' practice teaching. Engineering practice will be main content in the early stage; in middle stage, priority will be given to professional formation; and in later period, the priority will be given to professional 
promotion. The key is in later stage, and enterprise will select part of the students by virtue of "double-selection" to enter into enterprise in advance. Students shall follow the enterprise teachers to complete the actual working process. Enterprise teachers lead students to participate in actual engineering to strengthen and expand students' professional ability, and pay attention to the cultivation and application of students' comprehensive ability, rendering students a complete knowledge structure system from theory to practice design capability. Enterprises implement centralized training and make directional use; Enterprises and schools shall dispatch teachers mutually, to conduct two-way assessment and double guidance. School teachers and enterprise teachers jointly guide the students to complete such practice teaching links as decoration engineering practice and graduation design, and inspect students' internship, provide periodic assessment opinions, and conduct appraisal and evaluation on students' achievements during the internship; students take the practical engineering project as the main content of graduation design, and come back to the school for the defense with graduation design achievements; to be formally employed by the enterprise after graduation defense.

The implementation of "double qualified teachers and double guidance" is advantageous in fully discovering social resources, improving students' cultivation quality on the basis of setting up the double qualified teachers, to further maintain close cooperation between production and learning, which is of great significance for higher vocational colleges to strengthen faculty construction and seek breakthrough and development under new situation.

The architectural decoration engineering technology specialty of Yibin Vocational and Technical College has implemented the mode of "double qualified teachers and double guidance" in architectural decoration specialty for six years since 2010, including the cooperative enterprises of many famous decoration companies in Yibin, Luzhou, Nanchong, Suining, Chengdu and so on. In the process of implementation, such systems and implementation plans as implementing rules of "double qualified teachers and double guidance", student achievement appraisal and process control system are formulated. The students, who have involved in projects, will have an actual learning of decoration work flow while learning professional knowledge at school. Their comprehensive professional abilities get improved. At present, both the students' participation and enterprises' recognition are relatively high. During the years of implementing the "double qualified teachers and double guidance" teaching mode, it is basically a virtuous circle. On the one hand, we get the support from construction decoration enterprises; on the other hand, we also get the recognition and understanding of students and their parents. Exploit social resources fully, improve the cultivation quality of students, and further maintain the close cooperation between production and learning, establish two guidance teams of school and enterprise through the improvement in practice; student internship and employment docking has been realized, meeting the requirements and demands for the students majored in architectural decoration in higher vocational colleges by the society, to improve students' employment quality, and achieve the win-win effect among enterprises, schools and students, with the details as below.

First of all, through the cooperation, enterprises may conduct training in advance. On the one hand, they can select the prospective employees with certain quality and the professionals meeting enterprise demand in advance; on the other hand, they can complete the training on students in terms of corporate culture, job skills and practical ability before students' graduation, which may satisfy enterprises' urgent demand for talents in a fast and good manner, which greatly mobilizes the enterprises' enthusiasm to participate in the school's learning and working alternation, and change the enterprise from passive to active.

Secondly, through cooperation, schools have broken through the difficulty in practice teaching outside school, and realized the comprehensive and engineering application problems which cannot be broken in single course training, and have avoided the vicious cycle of high investment and low efficiency. At the same time, the outside school mentor resources are utilized effectively, and effectively made up the quantity and quality problems in school teachers; and by introducing in advanced technology of the industry, and accumulate experience and typical cases for teaching, the school teachers' professional skill and the ability to serve the society is improved, which has solved the problem of higher vocational college servicing local economy and meeting the industrial demand; and have solved the problem of disjunction between higher vocational development and teaching content, skill level, technical level as well as unemployment development; and have solved the problem of vocational education and social education.

Thirdly, students are the biggest beneficiaries of this cooperation. In the practical engineering, students have not only improved their language ability, professional skills, but also expanded their horizon, and strengthened the confidence, laying a good foundation for their future career. Because students are still in the process in teaching while they are entering into the enterprise to practice, so they must obey the school teaching arrangement, and they will slowly walk over the internship period and overcome pain and tiredness with the requirements of school's practice discipline and the strict discipline of the enterprises. Many years' practice tells us that students will be changed after the internship, as their career consciousness is enhanced, and they become mature and know how to learn, how to design their own career. Make students quickly integrate into the enterprise and become a useful person quickly. Realize excellent students to be employed with priority after graduation, and once they hold the posts, they can take over tasks, to really realize the goal of higher vocational colleges to cultivate the advanced and practical senior technology talents.

\section{CONCLUSION}

The reform of talent cultivation mode of higher vocational colleges is an essential method to enhance students' employment and entrepreneurship ability effectively following the law of higher vocational education. We should explore actively and practice boldly, to constantly perfect and improve 
the teaching mode of "double qualified teachers and double guidance", and cultivate more talents with high quality and high sills meeting industry requirements for architectural decoration enterprises.

\section{REFERENCES}

[1] Wu Xiaoxin, Li Mo. Research on Practice Teaching Problems in Higher Vocational Colleges and its Countermeasures [ J ] Management \& Technology of Small and Medium Sized Enterprises 2009 (10) 